\title{
THE INFLUENCE OF QUENCHED-IN AND THERMAL VACANCIES UPON SHORT-RANGE-ORDER FORMATION IN A Ni 11.4 AT \% Cr ALLOY
}

\author{
H. HEIDSIEK, R. SCHEFFEL and K. LÜCKE
}

Institut für Allgemeine Metallkunde und Metallphysik, RWTH Aachen, W.-Germany

\begin{abstract}
Résumé. - Les anomalies de résistivité après le traitement thermique d'alliages dont un composant au moins est un métal de transition, ont été traitées par différents auteurs déjà. L'accroissement anormal de la courbe de résistivité en fonction de la température a été attribué à la formation de l'état appelé $\langle\mathrm{K} »$ des alliages.

Dans le présent exposé, l'alliage $\mathrm{Ni} 11,4 \%$ at $\mathrm{Cr}$ a été réétudié. Les formes des courbes isochrones et isothermes mesurées sont très semblables à celles trouvées pour un alliage $\mathrm{Au} 15 \%$ at $\mathrm{Ag}$. C'est la raison pour laquelle l'analyse basée sur la diffusion de lacunes et la formation d'ordre à courte distance, telle que développée pour l'alliage $\mathrm{Au}-\mathrm{Ag}$, a été appliquée aussi aux expériences $\mathrm{NiCr}$. Ici aussi les valeurs autoconsistantes trouvées pour les énergies de formation et de.,migration de lacunes ainsi que l'énergie d'activation d'autodiffusion sont en accord avec les valeurs déjà connues.

Abstract. - Different authors have reported upon resistivity anormalities after thermal treatment of alloys with at least one component being a transition metal. The abnormal increase in the resistivity $v s$. temperature curve was attributed to the formation of the so-called « $\mathrm{K} »$-state of the alloys.

In the present contribution the alloy $\mathrm{Ni} 11.4$ at $\% \mathrm{Cr}$ has been re-investigated. The shapes of the measured isochronal and isothermal curves are very similar to those found on an $\mathrm{Au} 15 \mathrm{at} \% \mathrm{Ag}$ alloy. For this reason the analysis based on vacancy diffusion and short-range-order formation, as developed for the $\mathrm{Au}$-Ag-alloy has been applied also to the $\mathrm{NiCr}$ experiments. Also here selfconsistent values for the enthalpies of formation and migration of vacancies as well as the activation enthalpy of selfdiffusion could be determined in good agreement to the values found in literature.
\end{abstract}

1. Introduction. - In the early fifties, detailed investigations were made on the electrical resistivity of alloys with at least one component being a transition metal [1-5].

For instance Thomas [2] reports about three anormalities in resistivity measurements in $\mathrm{NiCr}$ alloys :

1) The resistivity $v s$. temperature curve is not linear, but « $\mathrm{S} »$-shaped.

2) After quenching from high temperatures the resistivity of a sample increases during an annealing treatment at lower temperature.

3) In contrast to the behaviour of pure metals and many alloys the resistivity of the samples can be decreased by cold deformation.

The author assumed that these anormalities were caused by the so-called « $\mathbf{K}$-state » which should arise in these alloys at low temperatures $\left(^{1}\right.$ ). However, no detailed information has been provided as to what this state should be microscopically. Although it was assumed that diffusion should control the formation of this state, ordering phenomena were excluded because ordering was assumed to always decrease the electrical resistivity as it is found for long-rangeorder formation. In this paper the alloy $\mathrm{Ni} 11.4$ at \%

(1) The letter « $\mathrm{K}$ » stands for the German word « Komplexe ».
$\mathrm{Cr}$ has been reinvestigated. Analogies to comparable $\mathrm{Au}-\mathrm{Ag}$ results shall be shown.

2. Experimental Procedure and Results. - The specimens were $30 \times 3 \times 0.1 \mathrm{~mm}$ cut out of a foil composed of $\mathrm{Ni} 11.4$ at \% $\mathrm{Cr}$. They were annealed by directly applied electric current in a hydrogenatmosphere in order to prevent oxidation. After each annealing step they were quenched with more than $5000^{\circ} \mathrm{C} / \mathrm{s}$ by application of a specially designed hydrogen shower. After each quenching they were put into a bäth of methanol at $-20^{\circ} \mathrm{C}$ in order to measure the electrical resistivity. The annealing was performed either isothermally or isochronally. (More experimental details will be given in a further paper.)

2.1 ISOCHRONAL EXPERIMENTS. - Figure $1 b$ shows the results of three isochronal experiments. First the specimen was quenched from $1000^{\circ} \mathrm{C}$ and stepwise annealed for $60 \mathrm{~min}$, starting at the annealing temperature $T_{\mathrm{a}}=100^{\circ} \mathrm{C}$ and increasing $T_{\mathrm{a}}$ by $50^{\circ} \mathrm{C}$ per step. The measured resistivity values are plotted versus the corresponding annealing temperature. Figure $1 b$ shows that an annealing treatment of $60 \mathrm{~min}$ at $T_{\mathrm{a}}=100^{\circ} \mathrm{C}$ and $T_{\mathrm{a}}=150^{\circ} \mathrm{C}$ is not sufficient to cause remarkable changes in the state of the specimen. At $T_{\mathrm{a}}=200^{\circ} \mathrm{C}$, however, an increase of the resistivity 


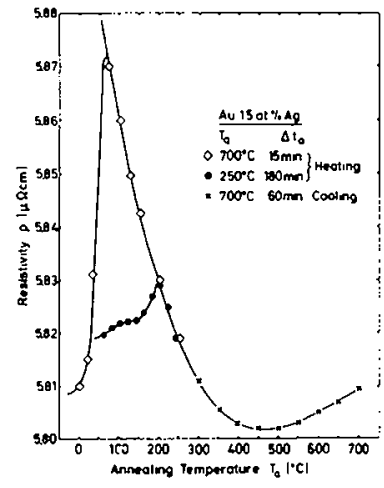

a)

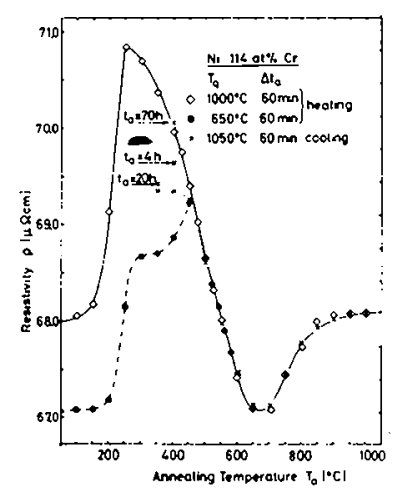

b)
FIG. $1 a, b$. - Resistivity $\rho$ of two different alloys (measured at $T_{\mathrm{M}}=-40^{\circ} \mathrm{C}$ in the case of $\mathrm{Au} 15$ at $\% \mathrm{Ag}$ and $T_{\mathrm{M}}=-20^{\circ} \mathrm{C}$ for $\mathrm{Ni} 11.4$ at $\% \mathrm{Cr}$ ) versus annealing temperature $T_{\mathrm{a}}$ during isochronal annealing after quenching from different temperatures $T_{\mathrm{q}}$.

of $1.5 \%$ is observed, and for $T_{\mathrm{a}}=250^{\circ} \mathrm{C}$ a maximum value is reached. Then the curve decreases with increasing annealing temperature, passes through a minimum at $T_{\mathrm{a}}=650^{\circ} \mathrm{C}$, increases again and enters a plateau at $T_{\mathrm{a}}=900^{\circ} \mathrm{C}$.

Repeating the experimental procedure with decreasing annealing temperature, nearly identical resistivity values were obtained. However, below $T_{\mathrm{a}}=450{ }^{\circ} \mathrm{C}$ the measured resistivity values are obviously smaller than the corresponding values of the heating experiment : Finally, at $T_{\mathrm{a}}=350^{\circ} \mathrm{C}$ the curve enters a plateau and even further isothermal annealing at this temperature for 20 hours is not sufficient to cause a remarkable re-increase of the resistivity. By raising the temperature again to $400{ }^{\circ} \mathrm{C}$ and annealing for 70 hours at this temperature the resistivity of the heating experiment can be reached.

In a third isochronal experiment the specimen is quenched from $600^{\circ} \mathrm{C}$ and annealed in the same way as described before. Here the resistivity increases immensely during the annealing treatment at $T_{\mathrm{a}}=250^{\circ}$ and $T_{\mathrm{a}}=300^{\circ} \mathrm{C}$. Between $T_{\mathrm{a}}=300^{\circ} \mathrm{C}$ and $T_{\mathrm{a}}=350^{\circ} \mathrm{C}$ the resistivity $v s$. annealing temperature curve has an inflection point, and after a re-increase of the resistivity found during annealing at $T_{\mathrm{a}}=400^{\circ} \mathrm{C}$ and $T_{\mathrm{a}}=450^{\circ} \mathrm{C}$, the same resistivity values of the isochronal experiments described above are attained.

Figure $1 a$ shows the corresponding isochronal experiments with an $\mathrm{Au} 15$ at \% Ag alloy which have been previously conducted [6]. Comparison of figures $1 a$ and $1 b$ shows that in principle both alloys behave in the same manner. As a similar strong analogy has been found also between isothermal experiments which will be discussed later, the analysis based on vacancy diffusion and short-range-order (sro) formation, as developed for the $\mathrm{Au}-\mathrm{Ag}$ alloys has been applied also to the $\mathrm{NiCr}$ experiments.
According to this analysis, the isochronal experiments should be interpreted in this manner :

By quenching from $T_{\mathrm{q}}=1000^{\circ} \mathrm{C}$ a non-equilibrium state is produced in the specimen : (i) the atoms are distributed at random, (ii) a supersaturation of vacancies is quenched-in. When the specimen is subsequently annealed at lower temperatures, the vacancies migrate to sinks and annihilate. Due to the vacancy diffusion, the atoms re-arrange themselves and tend to form energetically favoured configurations. In the case of AuAg alloys Schulze and Lücke have demonstrated [7] that sro formation leads to an increase of the resistivity.

As the mobility of the vacancies increases exponentially with the annealing temperature, the first isochronal experiment $\left(T_{\mathrm{q}}=1000^{\circ} \mathrm{C}\right)$ in figure $1 b$ shows that in $\mathrm{NiCr}$ the vacancies are still rather immobile at $T_{\mathrm{a}}=100^{\circ} \mathrm{C}$ or $T_{\mathrm{a}}=150^{\circ} \mathrm{C}$. At $T_{\mathrm{a}}=200^{\circ} \mathrm{C}$, however, observable diffusion takes place : Atoms diffuse to energetically favoured sites, i.e. the degree of sro and thus the resistivity increase. After the maximum is reached, the decreasing resistivity values are equilibrium values of sro corresponding to the respective annealing temperatures. In detail this was shown recently by Luicke, Haas and Schulze [6] for AuAg and AuPd alloys. In that paper also the reincrease of the resistivity with higher $T_{\mathrm{a}}$ is explained as a quenching effect; it shall not be discussed here.

The second isochronal experiment (cooling) shows that the process of sro formation depends immensely on the concentration of vacancies. As in this experiment the annealing temperature is always decreased by only $50^{\circ} \mathrm{C}$ per step, the corresponding concentration of surplus vacancies is respectively small and the concentration of thermal vacancies is reached quickly.

Thus ordering has to happen mostly by diffusion of thermal vacancies. As their concentration decreases exponentially with decreasing annealing temperature it finally turns out that the concentration which corresponds to $T_{\mathrm{a}}=450^{\circ} \mathrm{C}$ is not sufficient to establish the equilibrium of sro within the annealing time of $60 \mathrm{~min}$. At $T_{\mathrm{a}}=350^{\circ} \mathrm{C}$ the concentration of thermal vacancies is already so small that the equilibrium value cannot be reached with limited times [8]. At $T_{\mathrm{a}}=400^{\circ} \mathrm{C}$, however, this is still possible within 70 hours.

In the third isochronal experiment $\left(T_{\mathrm{q}}=650^{\circ} \mathrm{C}\right)$ the concentration of the quenched-in surplus vacancies is about 100 times smaller compared with $T_{\mathrm{q}}=1000^{\circ} \mathrm{C}$. Consequently, less atom jumps can happen during equal annealing times and at equal annealing temperatures : A comparison of the experiment with $T_{\mathrm{q}}=1000^{\circ} \mathrm{C}$ shows that at $T_{\mathrm{a}}=100^{\circ} \mathrm{C}, 150^{\circ} \mathrm{C}$, $200^{\circ} \mathrm{C}$ and $250^{\circ} \mathrm{C}$ the resistivity increase is respectively smaller. At $T_{\mathrm{a}}=300^{\circ} \mathrm{C}$ the resistivity $v s$. annealing temperature curve enters a plateau. The surplus vacancies have annihilated too far and the thermal. concentration is still very small. Increasing the concentration of thermal vacancies by increasing 
the annealing temperature to $T_{\mathrm{a}}=400{ }^{\circ} \mathrm{C}$ and $450^{\circ} \mathrm{C}$ the equilibrium curve of sro can be reached finally.

A detailed discussion of figure $1 a$ is given by R. Scheffel, H. Heidsiek, and K. Lücke in [9]. A direct comparison of both diagrams shows that both alloys behave nearly the same although in the case of $\mathrm{NiCr}$ the annealing temperatures are raised about $200^{\circ} \mathrm{C}$. This gives already a hint that rather high values for the enthalpies of vacancy formation, migration and selfdiffusion should be expected.

2.2 ISOTHERMAL EXPERIMENTS. - These enthalpies could be determined by applying the Schulze-Lücke analysis [6] to the isothermal experiments shown in figure 2 . In the upper part of figure 2 the correspond-

a)

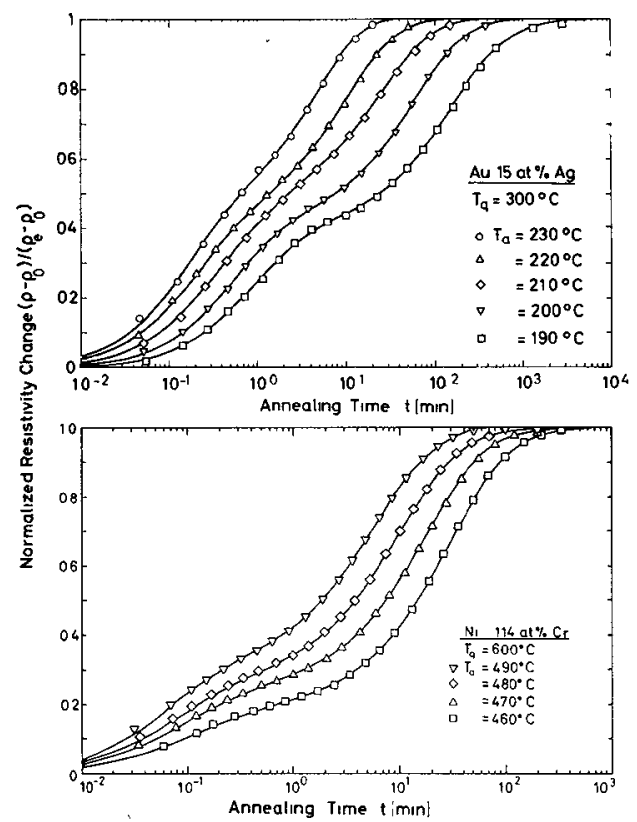

FiG. $2 a, b .-$ Normalized resistivity change of two different alloys versus annealing time (logarithmic time scale).

ing AuAg experiments are plotted. As described by Scheffel, Heidsiek and Lücke in [9], Schulze and Lücke have set up two semi-empirical equations to describe the vacancy annihilation and the resistivity changes due to sro formation :

$$
\begin{aligned}
-\frac{\dot{c}}{c_{0}-c_{\mathrm{e}}} & =\frac{1}{\tau_{\mathrm{v}}}\left(\frac{c-c_{\mathrm{e}}}{c_{0}-c_{\mathrm{e}}}\right)^{\alpha} \\
\frac{\dot{\rho}}{\rho_{\mathrm{e}}-\rho_{0}} & =\frac{1}{\tau_{\mathrm{s}}}\left(\frac{\rho_{\mathrm{e}}-\rho}{\rho_{\mathrm{e}}-\rho_{0}}\right)^{\beta} .
\end{aligned}
$$

Here $1 / \tau_{v} \sim v$ is a characteristic time for the annihilation of the vacancies with $v$ being the jump frequency. Respectively, $c_{0}$ is the initial value of the vacancy concentration and $c_{\mathrm{e}}$ the equilibrium value which depends on the annealing temperature $T_{\mathrm{a}}$. Accordingly, the equation :

$$
\frac{1}{\tau_{\mathrm{s}}} \sim v c
$$

is a characteristic time for the sro formation. $\left(1 / \tau_{\mathrm{s}}\right.$ is not a constant, since $c$ is a function of time !) Furthermore, $\rho_{0}$ and $\rho_{\mathrm{e}}$ are the initial and the equilibrium values of the resistivity.

With these equations also the $\mathrm{NiCr}$ resistivity measurements can be very well described : figure 2 shows also the theoretical curves determined in a computer fit, which is based upon eq. (1) and (2). This analysis gives values of the parameters $\alpha, \beta, \tau_{\mathrm{v}}$ and $\tau_{\mathrm{s}}$ which agree with those of the AuAg experiments.

A determination of the formation enthalpy of vacancies can be directly given from figure 3 . It shows

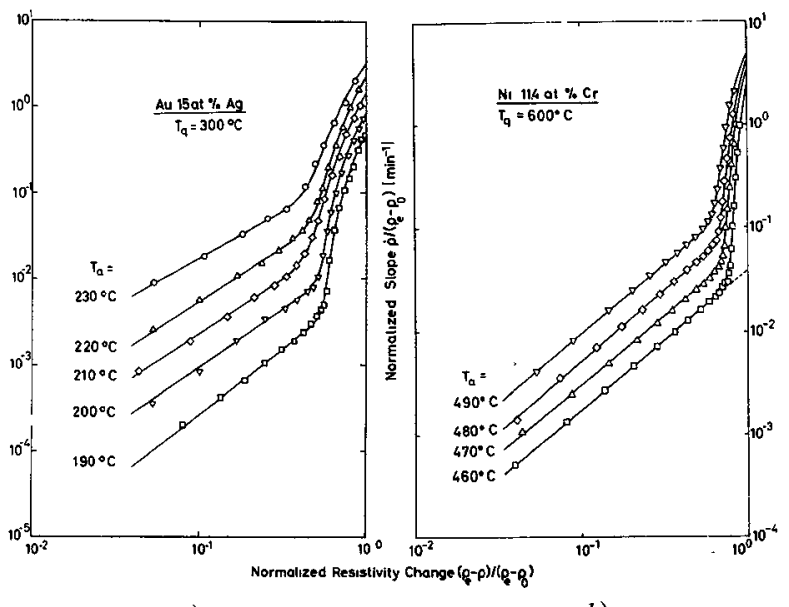

a)

b)

Fig. $3 a, b .-$ Normalized slope versus normalized deviation of the resistivity from the equilibrium value obtained from figure $2 a, b$.

the normalized slope $\dot{\rho}$ plotted vs. the normalized resistivity change, both are plotted in logarithmic scales. In the case of AuAg, Scheffel, Heidsiek, and Lücke [9] have discussed this kind of diagram in detail : It was demonstrated that along the straight part of the curves ordering happens by the diffusion of thermal vacancies $\left(c=c_{\mathrm{e}}\right)$, while during the bent part of the curves sro formation occurs with annihilating surplus vacancies. It can be shown that the intersect of the extrapolated straight line is proportional to

$$
\frac{1}{\tau_{\mathrm{s}}}=\frac{1}{\tau_{\mathrm{s}_{\mathrm{e}}}} \sim v c_{\mathrm{e}}
$$

with

$$
c_{\mathrm{e}} \sim \exp \left\{-H_{\mathrm{F}} / k T_{\mathrm{a}}\right\} .
$$

As for $t=0$ there is

$$
\frac{1}{\tau_{\mathrm{s}}}=\frac{1}{\tau_{\mathrm{s}_{0}}} \sim v c_{0}
$$


one can easily calculate for each experiment the enthalpy of vacancy formation, by applying the equation :

$$
H_{\mathrm{F}}=-\frac{k \cdot \ln \left(c_{\mathrm{e}} / c_{0}\right)}{T_{\mathrm{a}}^{-1}-T_{\mathrm{q}}^{-1}} .
$$

Thus we obtain a mean value of $H_{\mathrm{F}}=1.7 \mathrm{eV}$ in agreement with literature [10].

Furthermore, the vacancy migration enthalpy $H_{\mathrm{M}}$ as well as the activation enthalpy of selfdiffusion $Q$ can be evaluated from the characteristic times $\tau_{s_{0}}$ and $\tau_{\mathrm{s}_{e}}$. For $T_{\mathrm{q}}=$ const., $1 / \tau_{\mathrm{s}_{0}}$ remains only a function of the jump frequency $v\left(T_{\mathrm{a}}\right)$. Thus, $H_{\mathrm{M}}$ can be obtained by an Arrhenius plot, as shown in figure 4. Here a value of $H_{\mathrm{M}}=1.1 \mathrm{eV}$ is obtained.

Due to $1 / \tau_{\mathrm{s}_{\mathrm{e}}} \sim v c_{\mathrm{e}}$ the activation enthalpy of selfdiffusion $Q$ can be evaluated in the same way (figure 4). We obtain

$$
Q=2.8 \mathrm{eV} \text {. }
$$

3. Conclusions. - In this paper it is shown that both alloys behave nearly the same. The NiCr experiments can be described by the same semi-empirical eq. (1) and (2). Since the analysis gives identical values for the reaction orders $\alpha$ and $\beta$ it can be concluded that short range ordering and the formation of the $\mathrm{K}$-state are identical or at least very similar processes. Furthermore, the selfconsistent values for $H_{\mathrm{F}}, H_{\mathrm{M}}$

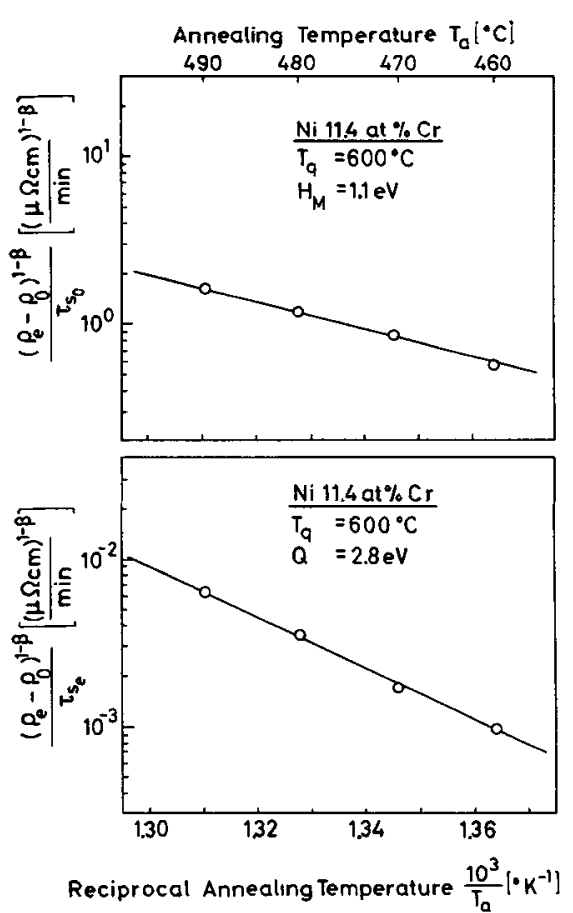

FIG. 4. - Arrhenius-plots of the quantities $\left[\tau_{s}\left(\rho_{e}-\rho_{0}\right)^{\beta-1}\right]^{-1}$ obtained from the axis intercepts in figure $3 b$.

and $Q$ prove the assumption that in both alloys sro formation is not only controled by the annihilation of surplus vacancies, but also by the diffusion of thermal vacancies.

\section{References}

[1] Thomas, H., Z. Metallkde. 41 (1950) 185.

[2] ThOMAs, H., Z. Phys. 129 (1951) 219.

[3] TAYLOR, A., Hinton, K. G., J. Inst. Metals 81 (1952-53) 1429.

[4] NordheIm, R., Grant, N. J., J. Inst. Metals 82 (1953-54) 440.

[5] MülleR, H. G., SCHulzE, H. A., Z. Metallkde. 48 (1957) 72.

[6] Lücke, K., HaAs, H., Schulze, H. A., J. Phys. Chem. Solids 37 (1976) 979.
[7] Schulze, H. A., LüCKe, K., Acta Met. 20 (1972) 529.

[8] Andries, J., Boon, W. G., Radelaar, S., Phys. Lett. 38A (1972) 459 .

[9] Scheffel, R., Heidsiek, H., LüCke, K., J. Physique Colloq. 38 (1977) C7.

[10] AdDa, Y., Philibert, J., La Diffusion dans les Solides (Presses Univ. de France, Paris) 1966. 